\title{
DIAGNÓSTICO DO AGRONEGÓCIO DO MELÃO (Cucumis melo L.) PRODUZIDO EM MOSSORÓ/RN: ESTUDO DE CASO EM TRÊS EMPRESAS PRODUTORAS
}

\author{
Alan Martins de Oliveira ${ }^{1}$, Auderlan Figueiredo Gurgel ${ }^{2}$ e Luiz Carlos Rodrigues de \\ Lima $^{2}$ \\ ${ }^{1}$ Mestre em Agronomia, Eng ${ }^{o}$ Agrônomo, Professor do Dpto. de Administração da \\ Faculdade do Vale do Jaguaribe - FVJ, Aracati-CE. \\ amoliveira36@uol.com.br \\ ${ }^{2}$ Estudantes de Graduação em Administração com habilitação em Agronegócio da \\ Faculdade do Vale do Jaguaribe - FVJ, Aracati-CE.
}

Recebido em Março de 2005 e Aceito em setembro de 2005

\begin{abstract}
RESUMO
Com o objetivo de realizar um diagnóstico do agronegócio do melão (Cucumis melo L) produzido no município de Mossoró/RN, elaborou-se o presente estudo de caso. Foram entrevistados gestores de três das maiores empresas produtoras de melão com sede no município. Como resultados, constatou-se que a união de produtores, governo e parceiros em torno do arranjo produtivo do melão, é uma condição fundamental para a manutenção e ampliação do mercado. Verificou-se que os maiores entraves do agronegócio, na ótica das empresas analisadas são: a desorganização do setor; o limitado apoio dos órgãos do governo quanto ao incentivo à produção, comercialização, logística, financiamento e assistência técnica; as barreiras tarifárias e não tarifárias dos países importadores; e a taxação na produção de frutos no Brasil com incidência de juros altos, prejudicando a competividade.
\end{abstract}

Palavras-chave: Cucumis melo L - Comercialização do melão - Agronegócio.

\section{DIAGNOSIS OF AGRIBUSINESS OF THE MELON (Cucumis melo L.) PRODUCED IN MOSSORÓ/RN: CASE IN THREE PRODUCING COMPANIES}

\begin{abstract}
With the objective of accomplishing a diagnosis of the agribusiness of the melon (Cucumis melo L) produced in the municipal district of Mossoró/RN, it was elaborated to present case. Managers of three of the largest companies producing of melon were interviewed with thirst in the district. As results, it was verified that the union of producers, government and partners around the productive arrangement of the melon, are a fundamental condition for the maintenance and amplification of the market. In the optics of the analyzed companies they are: the production disorder; the limited support of the government's organs with relationship to the incentive to the production, commercialization, logistics, financing and technical attendance; the barriers tariff and not tariff of the countries importers; and the taxation in the production of fruits in Brazil with incidence of high interests.
\end{abstract}

Key-words: Cucumis melo L - Commercialization of the melon - Agribusiness. 


\section{DIAGNÓSTICO DO AGRONEGÓCIO DO MELÃO (Cucumis melo L.) PRODUZIDO EM MOSSORÓ/RN: ESTUDO DE CASO EM TRÊS EMPRESAS PRODUTORAS}

\section{INTRODUÇÃO}

No Brasil, fatores como a grande extensão territorial, diversificação edafo-climática e disponibilidade hídrica, fundamentais na fruticultura, são características ambientais existentes e que tornam o país um dos mais favoráveis ao desenvolvimento desta atividade.

Em função de tais características, o Brasil é atualmente o terceiro maior produtor mundial de frutas frescas do mundo, com um PIB agrícola da ordem de 11 bilhões de dólares, gerando 4 milhões de empregos diretos, só na fruticultura. SECEX/MDIC (BRASIL, 2005).

O potencial agrícola brasileiro é enorme. O país tem quase $20 \%$ da área agricultável disponível do planeta. Quase 70\% do nosso território é agricultável. O novo cenário mundial, juntamente com as mudanças internas que vêm ocorrendo no setor agrícola, como a abertura comercial e a estabilização da economia estão propiciando um forte crescimento do agronegócio. (NEVES, 2002, p. 35).

Quanto à Região Nordeste, a fruticultura vem ao longo das duas últimas décadas substituindo as atividades agrícolas tradicionais no sertão, como cultivo de feijão, algodão e milho. A razão para isto é que a produção de frutos remunera melhor, trazendo maiores chances de crescimento para os produtores, sendo atualmente uma das atividades que mais gera emprego e que mais contribui com o superávit da balança comercial no Brasil.

A atividade se destaca na Região com culturas como manga, caju, uva, mamão e melão. Esta última, segundo Souza Neto et al. (2003), tem $90 \%$ da sua produção nacional nos estados nordestinos, cabendo ao Rio Grande do Norte 63\%.

A produção de melão ao nível deste Estado, se concentra no Agropólo de MossoróAçu, que abrange outros municípios como Baraúna, Apodi e os da região conhecida como Baixo Açu, que conforme a Revista Globo Rural (2003), possui aproximadamente 90 empresas de médio e grande porte produtoras de melão, principalmente do tipo amarelo.

Conforme SECEX/MDIC (BRASIL, 2005) a aceitação do melão brasileiro, sobretudo do Agropólo Mossoró-Açu é boa e encontra-se em franca expansão. As exportações nacionais de melão tiveram um crescimento de $115 \%$ nos últimos cinco anos. No ano de 2005, somente no primeiro trimestre, foram da ordem de US\$ 20.368.765, equivalentes a $20 \%$ das exportações nacionais de frutas.

Apesar do sucesso desta atividade, a comercialização do fruto ressente-se de uma melhor organização, especialmente no que se refere aos pequenos e médios produtores, que normalmente vendem sua produção para empresas âncoras que intermediam a exportação. Estas empresas requerem uma padronização das técnicas de produção, para que satisfaçam as exigências dos importadores. 
Existem também, os produtores com maior estrutura, que produzem e comercializam diretamente seus frutos. Porém, apresentam dificuldades para satisfazer as exigências técnicas e comerciais dos países importadores, que aumentam a cada dia o rigor quanto às questões de sanidade, inexistência de resíduos químicos, teores de açúcar, rastreabilidade dos frutos, bem como, as barreiras comerciais que são impostas, conforme relatado em 2003 no periódico Frutiséries, da Secretaria de Comércio Exterior do Ministério do Desenvolvimento, Indústria e Comércio Exterior (SECEX/MDIC):

Com relação à produção nacional [de melão] calcula-se que 35\% é orientada à exportação. Grande parte destina-se à Europa, onde as restrições às importações não têm impedido os embarques do produto nacional, embora já existam determinações da União Européia a fim de que o melão brasileiro tenha que ser acompanhado por certificado da implantação do 'Sistema de Produção Integrada’ para acesso a este mercado. (BRASIL, 2003, p. 02)

Assim, os caminhos percorridos pelo melão produzido na região de Mossoró, desde seu plantio até chegar às prateleiras dos mercados locais e CEASA's, das redes de supermercados do centro-sul do Brasil e de outros países como Reino Unido e Holanda, ressentem-se de um diagnóstico mais detalhado, levando em consideração os procedimentos de produção, logística, venda e distribuição.

Nesta perspectiva, este trabalho teve como objetivo principal, realizar um diagnóstico do agronegócio do melão produzido no município de Mossoró/RN, através de um estudo de caso em três empresas de grande porte.

\section{METODOLOGIA}

Em outubro de 2004, foram selecionadas 3 (três) empresas produtoras de melão localizadas em Mossoró, para consultas através de questionários dirigidos aos seus gestores, visando obtenção de dados relativos a esta atividade. O procedimento metodológico foi o estudo de caso, que segundo FARINA (1997, 03):

O estudo de caso descreve uma situação-problema real, vivida dentro de uma ou mais corporações e que exige decisões de cunho estratégico. Dessa forma, trata-se de problemática datada e vinculada a um conjunto de circunstâncias internas e externas à organização. Por outro lado, os elementos constituintes dessa situação -problema estão presentes em várias outras organizações, negócios e momento e ganha, portanto, generalidade, no sentido de contribuir para a tomada de decisão em ambientes e momentos diversos. Questões como sucessão, mudanças de regras do jogo competitivo, gargalos para o crescimento e formas organizacionais alternativas estão presentes nesses estudos de caso. 
As empresas analisadas, estão entre as maiores do ramo frutícola da região, que além de produzirem o fruto, também intermediam a exportação de pequenos e médios produtores, funcionando como empresas âncoras.

Seus gestores são profissionais com larga experiência neste agronegócio. As Empresas analisadas foram:

- NOLEM Comercial Importadora e Exportadora LTDA;

- AGROSOL Agricultura de Mossoró LTDA;

- SOAGRI Comércio de Importação e Exportação LTDA

Os dados obtidos foram sistematizados e seus resultados analisados e comparados com a literatura especializada.

\section{RESULTADOS E DISCUSSÃO}

\subsection{Dimensão Produtiva}

Em relação aos aspectos produtivos das empresas, pode-se mencionar:

a) NOLEM Comercial Importadora e Exportadora LTDA:

Fundada em 1997, a Nolem é atualmente a maior produtora e exportadora de melão do país, sendo responsável por 30\% das exportações do fruto e detentora de $40 \%$ do mercado nacional. A empresa produz seis tipos de melão: Valenciano Amarelo, Pele de Sapo, Orange Flesh, Cantaloupe, Gália e Charantais, todas visando o mercado externo, notadamente para a Inglaterra e Holanda, saindo pelos portos de Natal e Fortaleza.

A Nolem também produz mamão, acerola, caju, melancia e coco verde, visando uma diversificação de sua principal linha produtiva. No entanto, essas culturas ainda são produzidas em escala bem menor e somente para o mercado interno.

b) AGROSOL Agricultura de Mossoró LTDA:

A Agrosol foi fundada em 1980 e tem como principal atividade produtiva o plantio e comercialização de melão, utilizando as variedades: Goldex, Sancho, Solar King. Quanto ao plantio de outras culturas, menciona-se mamão, sorgo e manga, destinados para o mercado interno.

c) SOAGRI Comércio de Importação e Exportação LTDA:

A Soagri foi fundada em 1998 e tem a seguinte linha produtiva:

- Melão Amarelo: Variedades/híbridos AF 646, AF 642; Natal e High Brix.

- Melão Pele de Sapo: Variedade Sancho.

- Melão Gália: Variedades Solar King e Solar Net.

- Melancia: Variedade Mickey Lee.

No período de entressafra é realizada a rotação de culturas, com o plantio de milho e sorgo. 


\subsection{Dimensão administrativa}

A respeito do grau de formação dos gerentes das empresas de fruticultura (GRÁFICO 01), foi constatado que as fazendas analisadas estão priorizando a contratação de profissionais habilitados em gerenciamento, haja vista que o mal gerenciamento é possivelmente um dos fatores que contribui para o fracasso de uma série de empresas.

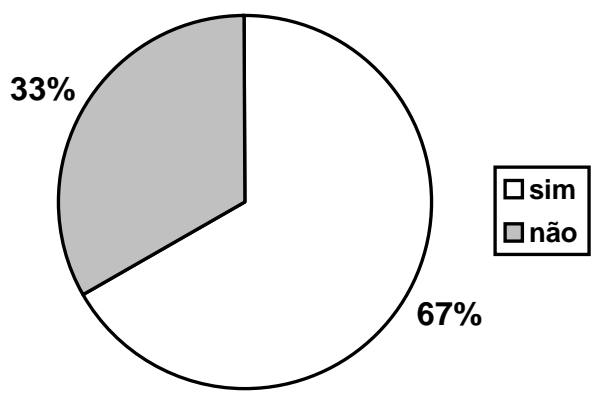

GRÁFICO 01 - Resposta em \% à pergunta: “A empresa possui algum(a) membro(a) da gerência formado(a) em administração de empresas?” feita a três gerentes de empresas de fruticultura de Mossoró-RN, 2004.

Um dos gerentes que respondeu “sim” a pergunta relativa ao GRÁFICO 01 justifica que para a empresa que ele administra:

A relevância de um administrador, compondo a gerência da empresa é de suma importância, pelo conhecimento obtido na graduação, principalmente em planejamento, organização, direção e controle, além das disciplinas coadjuvantes ou técnicas. Ou seja, a nossa empresa entende que a experiência é fundamental, mas a capacidade teórica do profissional é um elemento bastante considerado.

Ainda na perspectiva da administração, um ponto importante diz respeito à realização de financiamento das atividades produtivas, onde se verificou uma tendência ao não financiamento (GRÁFICO 02).

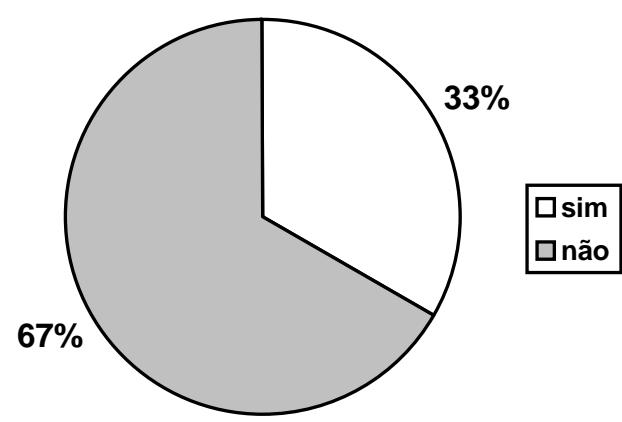

GRÁFICO 02 - Resposta em \% à pergunta: “Sua empresa já realizou financiamento alguma vez?” feita a três gerentes de empresas de fruticultura de Mossoró-RN, 2004. 
Uma justificativa a este fato foi fornecida por um dos gestores: "A Empresa não trabalha com capital de terceiros, toda sua produção é financiada pelas vendas [parcialmente antecipadas] e por capital próprio". Não obstante, a este respeito Zylbersztajn \& Neves (2002, p. 103) fornecem mais elementos:

Caso o projeto [agroindustrial] apresente insucesso e tenha sido financiado em grande parte por dívidas, os credores irão demandar um retorno certo, de acordo com as cláusulas contratuais preestabelecidas... Recursos próprios são mais tolerantes e se adaptam melhor a tais distúrbios.

\subsection{Cadeia produtiva do melão}

Os produtores referiram-se à cadeia produtiva do melão na região de Mossoró, com visível motivação, indicando que seu fortalecimento é fundamental para o desenvolvimento da atividade e da região, conforme elucidado nesta declaração de um meloeiro de Mossoró:

Na verdade, a preocupação das empresas hoje com toda a chamada cadeia produtiva, está ligada ao fato de que com o processo de globalização da economia, a tecnologia ficou acessível ao capital. Isto é, o que diferencia uma empresa de sucesso de outra que fracassa é, justamente, o que ela consegue agregar ao seu produto ou serviço.

O produtor prossegue:

Quando estabelecemos parcerias, no caso do melão, com a cadeia ascendente como os fornecedores de sementes (ajudando a desenvolvê-las no campo), embalagem (sugerindo mudança de tamanho, formato e composição do material), insumos em geral (obedecendo a mesma filosofia dos itens anteriores) e, com a cadeia descendente, como os transportadores (transportadores $e$ empresas de navegação) discutindo roteiros, épocas e composição das cargas; os distribuidores (melhorando os níveis de estoque e reposição dos produtos), os supermercados (promovendo campanhas e degustações) e enfim, o cliente final, que é a dona de casa (recebendo retorno e sugerindo formas de utilização dos produtos e receitas culinárias) estamos fortificando a cadeia e, conseqüentemente, fortificando a nossa fatia de mercado.

Tal depoimento tem ressonância no que foi preconizado por Araújo (2003, p.24):

A vantagem dos clusters $^{1}$, em relação a sistema isolado, está exatamente na integração com outros sistemas, de modo que há possibilidade de sinergismos entre diversas atividades, aproveitamento de produtos, subprodutos e resíduos de um sistema para outro, bem como possibilidade de utilização de estruturas

${ }^{1}$ Aqui entendido como sinônimo de cadeia produtiva. Para uma maior referência conceitual, é útil a leitura de Zylbersztajn \& Neves (2002). 
físicas para múltiplos sistemas, permitindo economias de escala, trocas de informações, menor dependência e segmentos externos, diminuição de custos, etc., enfim, como maior competitividade das empresas isoladamente e do conjunto.

\subsection{Comercialização do melão}

As três empresas investigadas têm no mercado externo a maior parte da destinação de seus frutos. Os produtores alegam que o fruto de primeira qualidade é quase totalmente destinado à Europa, onde os principais portos de distribuição são os de Roterdã, na Holanda e de Dover, na Inglaterra.

O abastecimento do mercado interno embora também ocorra, não se compara em termos de lucratividade para as empresas. O principal motivo para este direcionamento é o preço pago por fruto, que no mercado externo, apesar da necessidade de uma maior logística, é consideravelmente melhor que o mercado nacional.

Esta acertiva é corroborada pela Revista Globo Rural (2003, p. 33), também se referindo aos produtores de melão: “competir no mercado internacional, é bem mais atraente do ponto de vista dos preços, do que o interno”.

Outros mercados internacionais estão em fase de conquista, conforme observações dos gestores, como a Escandinávia, Alemanha e países orientais, mas isto é um processo demorado e existe pouco apoio dos órgãos governamentais no que tange aos incentivos, principalmente para os pequenos e médios produtores.

Sobre a comercialização do melão, Francisco de Paula Segundo, Diretor-presidente da COEX (Comissão Executiva da Área Livre de Mosca-das-frutas de Região de MossoróAçu-Areia Branca) em entrevista concedida a Revista Globo Rural, elucida parte dos entraves à comercialização do melão:

A produção local [de melão] escoa por estradas ruins, em caminhões velhos, prejudicando as frutas. Os produtores vêm reivindicando a extensão da ferrovia que liga Natal a Guamaré... mas o trem ainda não saiu do papel. Desenvolveria ainda mais a região e o próprio Estado, com o aumento da arrecadação. (Globo Rural, 2003, p.30)

Francisco Segundo continua:

Desta forma, muitos produtores locais e outros com fazendas também no Ceará passariam a exportar via Natal, porto recém modernizado, com armazéns frigorificados, e não mais por Pecém ou Mucuripe, no Ceará. Hoje o Pólo dispõe de 12 mil hectares irrigados. Poderia triplicar. (Globo Rural, 2003, p.30)

O depoimento do Presidente da COEX, é confirmado pelos administradores das empresas produtoras de melão, que acrescentam mais elementos de reivindicação junto aos órgãos públicos, ao responderem à pergunta "Que sugestão o senhor daria aos administradores públicos para otimizar a fruticultura em nossa região?”: 
Melhoria da infra-estrutura como melhores estradas para o escoamento da produção, interiorização da energia e água (visando o barateamento pela multiplicação do uso) e assistência técnica, principalmente ao pequeno produtor, que, em muitos casos, por não dispor de capital, terceiriza a sua produção para as médias e grandes empresas, desde que possuam qualidade garantida.

Ainda relativo à comercialização de frutas, outros elementos merecem destaque, como as barreiras tarifárias e não tarifárias imposta pelos importadores, bem como a necessidade do desenvolvimento de pesquisas voltadas para a fruticultura:

Os produtores nacionais devem estar atentos tanto às barreiras tarifárias e não tarifárias, quanto às exigências desses mercados. Outra questão importante está relacionada ao acompanhamento dos movimentos de pesquisa tecnológica de outros países e no país, tendo em vista a inserção de variedades mais ao gosto daqueles consumidores. (BRASIL, 2003, p.12)

Um outro ponto nevrálgico é apontado pelo dono da Nolem, André Gadelha, referindo-se ao problema da taxação da produção no Brasil: "A taxação é brutal, somos um país que exporta imposto, quando deveríamos imitar os países concorrentes que reduziram taxas de exportação e juros para incentivar a produção, gerar emprego e renda $e$ fortalecer as empresas”. (Globo Rural, 2003, p.30)

Ainda a esse respeito, o depoimento de um produtor de melão, o Sr. José Pereira, durante o $3^{\circ}$ Encontro Internacional de Agropólos como Estratégia de Desenvolvimento, ocorrido em Fortaleza/CE em 2002 é elucidativo:

Eu estava na Espanha, no ano passado, visitando um galpão de embalagem bastante sofisticado, e o produtor explicava que metade do investimento o governo dava a fundo perdido e a outra metade ele tinha vinte anos para pagar. É uma realidade diferente da brasileira. (Banco do Nordeste, 2002, p. 175)

Com efeito, os cuidados com a comercialização não se restringem ao mercado externo:

O mesmo cuidado deve estar relacionado ao mercado interno que vem se modificando ultimamente com exigências cada vez mais sofisticadas por parte dos consumidores no que se refere ao ponto certo de colheita, que confere ao produto teor adequado de brix $e$ coloração característica, dentre outros, quanto aos cuidados póscolheita. (BRASIL, 2003, p.12)

Os gargalos aqui apresentados a respeito da comercialização do melão, carecem de priorização por parte das organizações dos produtores e pelos órgãos governamentais; inclusive, fazendo jus ao discurso de posse do Ministro da Agricultura, Pecuária e 
Abastecimento do Governo Brasileiro, Sr. Roberto Rodrigues em Janeiro de 2002, quando elencou prioridades para o agronegócio brasileiro em três grandes grupos de ação:

- políticas públicas que garantam renda ao produtor rural, porque só isto pode fixá-lo em sua profissão;

- uma organização privada capaz de assumir as responsabilidades que o mercado global exige, de uma forma compartilhada com a ação pública;

- uma firme negociação internacional, nos fóruns multilaterais ou bilaterais em que o Brasil defenderá o acesso ao mercado do nosso agronegócio, contra o protecionismo dos países ricos que destrói nossos empregos. (BRASIL, 2004, p.02)

Os produtores do agropólo mossoroense fazem coro às afirmações do Ministro. Porém, as dificuldades de organização da cadeia produtiva do melão conduzem a um desequilíbrio, mostrando a fragilidade do segmento "dentro da porteira” em relação aos demais segmentos (produtores de insumos e máquinas, por exemplo), enfraquecendo todo o agronegócio.

Isto reflete a necessidade da organização dos produtores para o fortalecimento em si e de todo o conjunto responsável pela sustentação alimentar, social e macro/micro econômica do Brasil.

\section{CONCLUSÕES}

A união de produtores, governo e parceiros em torno da cadeia produtiva do melão é uma condição fundamental para a profissionalização da atividade, bem como para a manutenção e ampliação do mercado para os frutos produzidos na região de Mossoró.

Os Gestores de empresas produtoras de melão entrevistados neste trabalho foram unânimes quanto ao crescimento da fruticultura no agropólo, e concordam que dentre os entraves para o avanço desta atividade estão:

- A desorganização do setor;

- O pouco apoio institucional, dos órgãos do Governo quanto ao incentivo à produção, comercialização, logística, melhoria de estradas, financiamento e assistência técnica;

- As barreiras tarifárias e não tarifárias dos países importadores;

- Taxação na produção de frutos no Brasil e incidência de juros altos, prejudicando a competividade.

\section{REFERÊNCIAS}

ARAÚJO, M. J. Fundamentos de Agronegócios. São Paulo: Atlas, 2003.

A REPÚBLICA dos pomares. GLOBO RURAL. São Paulo, 2003. 
BANCO DO NORDESTE. Encontro Internacional de Agropólos como Estratégia de Desenvolvimento. III, 2002. Fortaleza. Anais... Fortaleza, Banco do Nordeste, 2002.

BRASIL. Ministério da Agricultura, Pecuária e Abastecimento. Discurso de posse do Ministro Roberto Rodrigues. 2002. www.agricultura.gov.br <acesso em 01.12.2004>

BRASIL. Ministério da Integração Nacional. Frutiséries 2 - Melão: Ceará. Brasília: MIN, 2003.

FARINA, Elizabeth (Coord.) Estudos de casos em agribusiness. São Paulo. Pioneira. 1997

SECEX. Secretaria de Comércio Exterior. http://www.portaldoexportador.gov.br. < Acesso em 19.06.2005>.

NEVES, M. F. (Org.). Gestão de negócios em alimentos. São Paulo, Pioneira Thomson Learning, 2002.

SOUZA NETO, E.R. de, MEDEIROS, J. F. de, LEVIEN, S.L.A., PORTO FILHO, F. de Q., MOURÃO, A.C., SOUZA, E.R. de. Produção de melão irrigado com águas de diferentes níveis de salinidade nas diferentes fases da cultura. In: Seminário de Iniciação Científica da ESAM, IX, 2003, Mossoró, Resumos Expandidos... Mossoró: CNPq/PIBIC/ESAM, 2003.p. 2-4.

ZYLBERSZTAJN, Dédio; NEVES, Marcos Fava. (Orgs) Economia e gestão dos negócios agroalimentares. São Paulo. Pioneira. 2002 